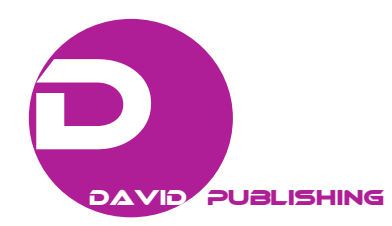

\title{
The Influence of Public Policies on Urban Mobility: A Comparative Study between Porto Alegre (Brazil) and Washington D.C. (United States)
}

\author{
Maurício Kunz ${ }^{1}$, Alcindo Neckel ${ }^{1}$, Henrique Aniceto Kujawa ${ }^{1}$, Angela Chiamentti ${ }^{1}$ and Eliane Thaines Bodah ${ }^{2}$ \\ 1. School of Architecture and Urbanism of Faculdade Meridional (IMED), Group of Studies and Research on Urban Mobility \\ (NEPMOUR), Passo Fundo/RS. CEP: 99070-220, Brazil;
}

2. Department in Horticulture, University of Washington, 910 S Meadow St Colfax WA 99111, USA

\begin{abstract}
Increasing urbanization rates observed in the last decades have significantly contributed to a higher number of travelers to urban environments. The objective of this study was to identify measures and factors that encourage the use of alternative transportation in the cities of Washington D.C., USA and Porto Alegre, Brazil. The methodology used to compare these two cities was an evaluation of their urban mobility plans, including strategic analyses and measures to promote the use of public transport. This approach was based on factors described in the following document: "Urban Sustainability: Impacts of Economic Development and Their Consequences on the Process of Urbanization in Emerging Countries”, prepared by the United Nations. The results indicate different planning strategies, ranging from focusing on tax integration policies in order to become more financially attractive to the user, to using different modes of mass transportation integrated with active mobility. In Washington D.C., an innovative strategy was developed in preparation to forecast scenarios, as the measures comprised projection for the year 2040, which will respond to mobility demands in the coming decades.
\end{abstract}

Key words: Mobility analysis, urbanism, urban infrastructure, sustainable strategy.

\section{Introduction}

Urban mobility involves cultural and political factors of the contemporary society, "whether in a structured or behavioral way" [1]. Recent studies point out that public policies and measures related to urban mobility should be aimed at stimulating the use of collective transportation, and active forms of mobility. Therefore, such studies would be also contributing to good social and environmental practices in cities [1, 4].

By highlighting factors that are related to urban mobility, which correspond to the different types of population movement in relation to urban environment, reaching urban sustainability has become a priority and a challenge for planning and research sectors over the

Corresponding author: Alcindo Neckel, Dr.; research fields: technology, project and management of the built environment, cemeteries environmental impacts, and sustainability. E-mail: alcindo.neckel@imed.edu.br. last decades [2].

Recent research reveals the need for "appropriate transportation policies and programs using evidence-based interventions that require full understanding of urban mobility patterns" [5]. Studies focusing on different transport systems in relation to the characteristics of urban movement are extremely important to rethink internal adaptations about ways that cities have been designed $[3,4,6]$.

The massive increase in the number of cars, where many of these vehicles either travel over the speed limit, or remain stopped for hours on roads, when the flow should be constant in relation to the allowed speed limits [4].

These traffic problems can be solved using technical measures and research which aim at sustainable urban mobility in relation to meeting the population needs. Therefore, the importance of public initiatives is 
evident which will benefit urban mobility factors and, therefore, they will make transport of people more feasible [7].

Studies indicate the existence of alternative systems to increase favorable rates of urban mobility, such as the use of public transport and bicycle lanes, thus becoming "an alternative of sustainable transport, fuel economy, quality improvement in public health, smart urban growth initiative, as well as climate change considerations" decreasing the carbon footprint [8].

A suitable solution for transportation issues in Brazil regards and the implantation of factors that will bring improvements to the urban mobility issues will require governmental interest in urban planning, in addition to financial investments [9].

Achieving sustainable urban mobility strategies, outlined in a document prepared at the Rio +20 , are highlighted in the book Urban Sustainability: "Impacts of Economic Development and Their Consequences on the Process of Urbanization in Emerging Countries". This book points out aspects for standardization of mobility necessary for sustainability, such as "articulation of urban conceptions and public transport network in relation to this standard; tax injustice and regressive taxation of mobility; allocation of resources in contradiction to the inclusion sustainability discourse"; and "structuring of economic activities in the production chain" [10]. Rio +20 was a high impact event that engaged the Brazilian government, the MMA (Brazilian Ministry of Environment), and the UN (United Nations).

Once a review and theoretical reflection on urban mobility for practical applicability was concluded, the general objective of this research became to conduct a comparative analysis on the profile of two big cities, namely, Porto Alegre (Brazil) and Washington D.C. (United States), regarding their urban mobility, and how it relates to their density and expansion.

This study is developed aiming to fulfill the following aspects: to identify the way these two cities were designed; to identify the projection of measures that contribute to the construction of a city with good mobility and sustainability; and to propose ways to contribute to their urban master plans and urban mobility plans. Urban planning is extremely important for designing and implementing public urban mobility policies $[6,11]$.

The comparative analysis conducted in this research is mainly justified by two important factors. Firstly, although these cities have similar population densities, they do not have the same geopolitical importance in their countries, that is, Washington D.C. is the capital of the USA, whereas Porto Alegre is the capital of Rio Grande do Sul, a Brazilian State. Secondly, Porto Alegre is located in an emerging country whereas Washington D.C. is located in a developed country. Therefore, it will be feasible to identify common elements and differences in these two cities.

\section{Materials and Methods}

In this research, a quantitative method was used to analyze several variables in a systematic way [12]. The variables analyzed comprise population density, population growth, income, number of automobiles, and distribution of transport modes used in Porto Alegre and in Washington D.C. At the same time, aspects of the qualitative method were used to document and conduct iconographic analyzes of urban mobility plans in these two cities.

The analyzed variables were selected based on the document produced by the UN (2014) entitled "Urban Sustainability: Impacts of Economic Development and Their Consequences on the Process of Urbanization in Emerging Countries" [10]. It analyzes the relationship between urban mobility and city conformation. These analyzes consider the influence of economic aspects on the patterns of daily movement of the population carried out for production and consumption. It also offers a discussion on the main factors related to public policies aimed at the implementation of sustainable mobility. For instance, it approaches sector planning and public transport network concepts, financing 
mobility, management efficiency of the urban mobility system, control and transparency, and mobility and support system for green technology. These factors include the variables analyzed by the qualitative method in the present study.

Measures and strategies corresponding to the study variables characterized previously, were obtained in the urban mobility plans of the studied cities. In the case of Porto Alegre, the document analyzed is called "Urban Mobility Master Plan" [13], prepared by the EPTC (Public Transport and Mobility Company). While in the case of Washington D.C., the document analyzed is called "moveDC: The District of Columbia's Multimodal Long-Range Transportation Plan", developed by the District Department of Transportation [14].

Data collection on the measures and strategies aimed at sustainable mobility in the studied cities, through comparative analyses, intends to diagnose the guidelines and measures that show effectiveness in the improvement of public transportation systems and promote alternative modes of transportation.

Fig. 1 shows the correlations between the analyzed variables.

\section{Results and Discussion}

Washington D.C., the capital of the United States, is located in the District of Columbia, and has an estimated population of 672,228 , spread over an area of approximately $177 \mathrm{~km}^{2}$ [15, 16]. Its metropolitan region comprises about 5.8 million people, which makes it the seventh largest metro area in the USA. As a capital, it houses the branches of the three governmental powers, namely the Congress, the President, and the Supreme Court. Whereas Porto Alegre is located in the extreme southern region of Brazil, in the state of Rio Grande do Sul (Fig. 1), it has a population of $1,481,019$ [17, 18], and it is part of a metropolitan region that is one of the most important cities with population of approximately 4.3 million people.

With regards to urban mobility, the Washington D.C. region, and its suburbs, are served by the Washington subway, which has 91 stations distributed in $188 \mathrm{~km}$ of lines that are used daily by more than one million passengers. Another means of public transportation is the Metrobus, responsible for more than 400,000 trips a day. However, to get to work on a daily basis, residents still prefer to travel by car, which is responsible for $41 \%$ of daily commuting, while $38 \%$ commute by public transport, $12.4 \%$ walk, 3.9\% use bicycle, and 4.7\% work from home [19].

In the city of Porto Alegre, the transportation system works in a trunk-fed manner, where the Trensurb (urban train) is fed by bus routes and therefore makes about 300 million trips a year. In daily commutes, public transportation is the most used mode accounting for $44.30 \%$ of the travels, while non-motorized modes

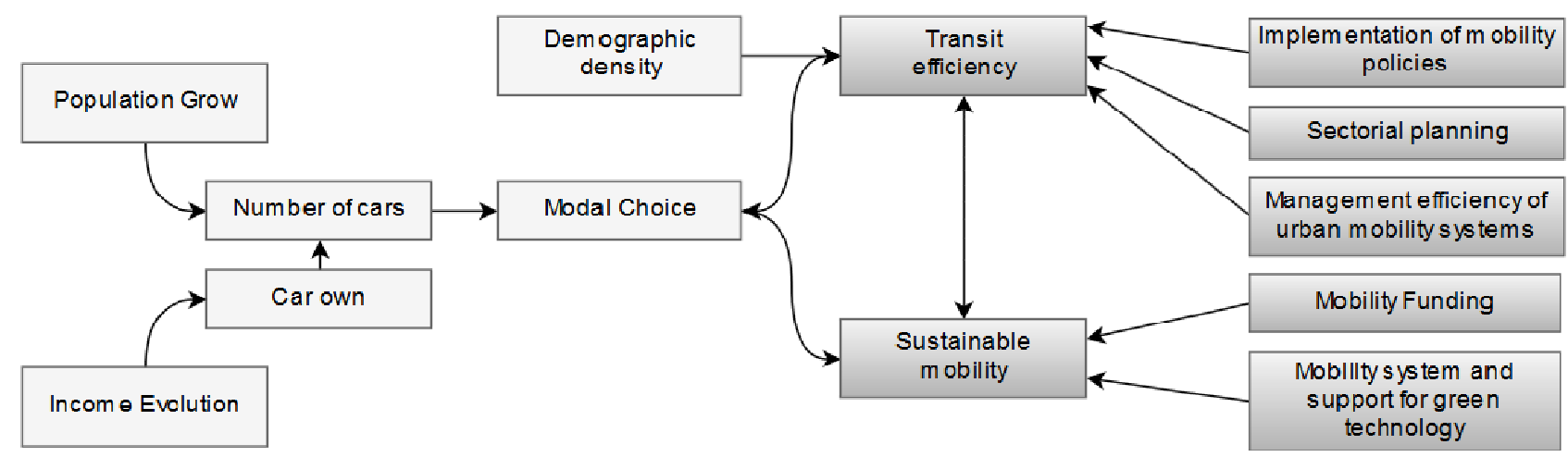

SUBTITLE

$\square$ Quantitative analysis $\square$ Qualitative analysis

Fig. 1 Analytic flow chart, showing the relationship between the analyzed variables. 
account for $29.90 \%$ and, cars only for $25.8 \%$ [20].

In addition to the characteristics of transport systems, factors related to demography and land occupation also are important factors of analysis in studies related to urban mobility. Different intensities of land use, promoting compactness or urban spreading directly influence the patterns of daily mobility adopted by the population.

The urban horizontalization and sprawl, a result of low constructed densities, increases the distances of daily mobility as well as decreases the efficiency of public transportation systems, which require demand agglomeration to enable high capacity systems $[10,21,22]$. Such context aligns one of the factors that makes individuals prefer motorized modes of mobility, and it is one of the causes of traffic saturation in central roads [23]. Thus, the importance of master plans that promote the use of soil compaction to reduce distances encourages alternative modes of transportation to the detriment of the motorized individuals.

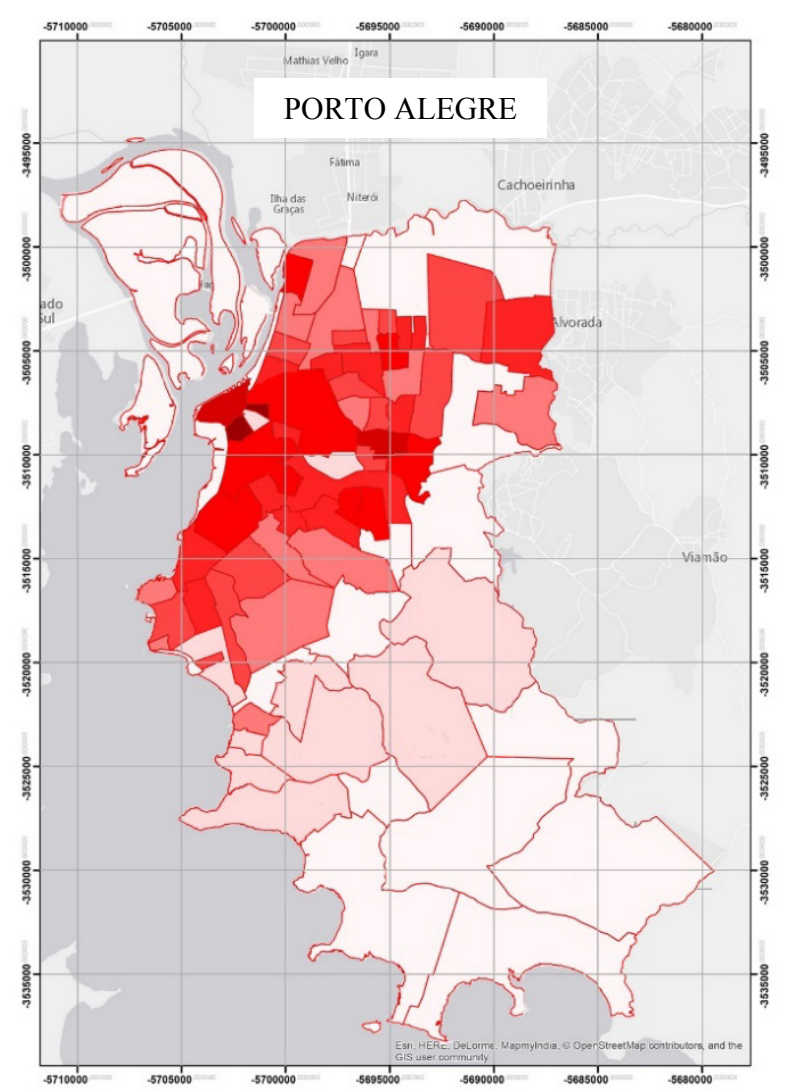

This context demonstrates indissociability of factors related to population density and urban mobility patterns. Thus, the analysis of the population distribution of these cities can present indicators to improve efficiency of the territory coverage by transport systems. Figs. 2 and 3 present, respectively, the population density (inhabitants/hectare) in Porto Alegre and Washington D.C.

In Porto Alegre (Fig. 2), high density is found at the waterfront towards the east side, where the first signs of urbanization are seen. There is a constant reduction of density as away from its center, thus resulting in a population distribution layout similar to a semicircle. The contrast between travel demands in the central area compared to the peripheral area, is a result of these different densities and leads to lower efficiency of service provided by the public transport in these peripheral areas. There is an inverse relationship between the extension of the transportation system and its efficiency $[10,23]$.

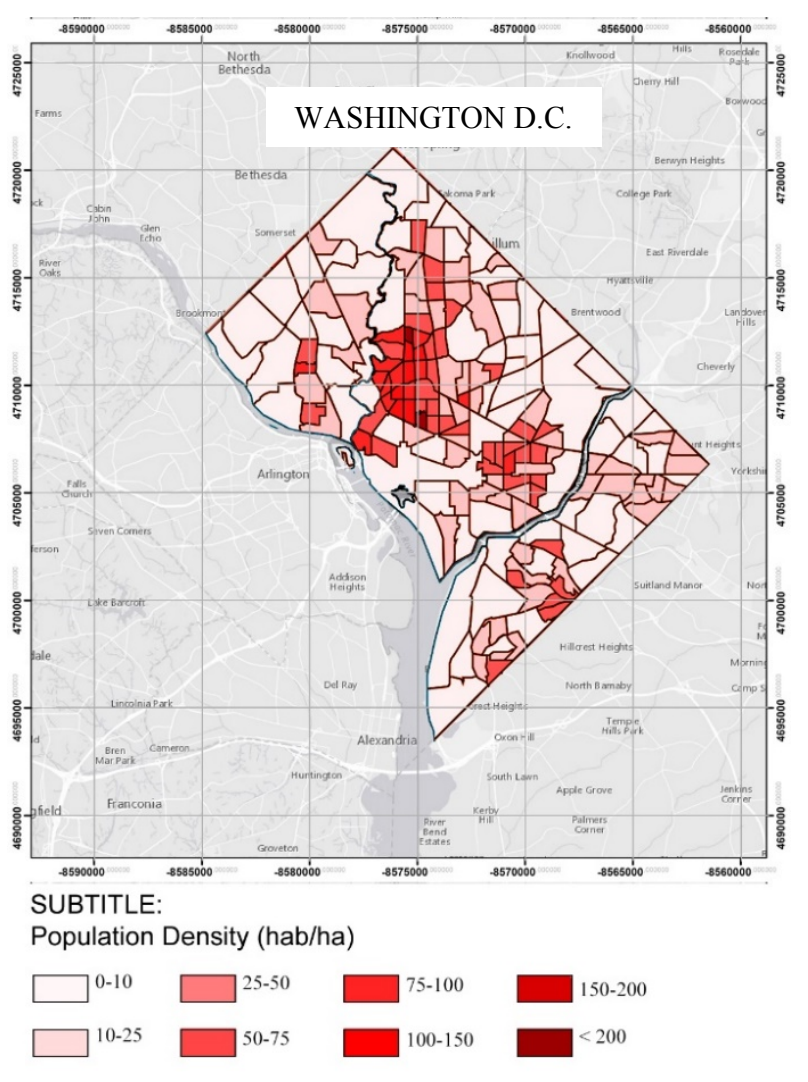

Fig. 2 Population density of Porto Alegre and Washington D.C. [17, 24]. 
The city of Washington D.C. has a distinct population distribution, which is more concentrated mainly near the geographic center of its urban perimeter. This radial distribution of population density tends to prioritize the mobility in the periphery-center route, carried out on radial transport axes. Bearing in mind that the coverage of the axes increases with the distance from the center, it is essential to facilitate the access of residents of the peripheral areas to these axes. Therefore, micro accessibility is a factor of great importance to promote growth of public transportation use.

In addition to the population layouts of these two cities, an analysis of population evolution, number of cars, number of passengers transported and per capita income was conducted from 2005 to 2015. This analysis aimed to verify correlations between the studied variables. Data in Table 1 shows improvement of the studied factors, analyzed over 10 years. Fig. 3 shows the correlations between variables, assigning index 1 to the values corresponding to the year 2005 .

Fig. 3 (graph) shows the correlations between the factors analyzed in Porto Alegre, where the relationship between the increase in income and increase in motorization rates can be noticed also through the increase in number of cars. Number of cars is proportionally higher than the population for the same period. Due to better income, an increase in motorization rates is observed, mainly in emerging countries, resulting in higher use of individual transportation by families, which would usually use public transportation [10, 29].

Combined with growth of income, another factor that may be related to the increase in motorization, in Porto Alegre, from 2008 to 2009 was the implementation of federal tax exemption policies (reduction of the Tax on industrialized products) for new cars, thus stimulating their acquisition and use [30].

In Washington D.C., an increase in motorization rate, accompanied by a decrease of number of passengers transported annually starting in 2008 is observed. Unlike Porto Alegre, there is no relationship with evolution of income.

In general, the increase in motorization rates in both cases is evident, revealing the need to implement public policies to control the use of cars and, therefore, makes cars less attractive than the public modes of transportation.

\subsection{Sector Planning: Design of a Public Transport Network}

The comparative analysis of cities plans reveals similarities in the guidelines adopted, aimed at the

Table 1 Population evolution, number of passengers transported, number of cars, and income per capita, from 2005 to 2015 in the cities of Porto Alegre, Brazil, and Washington D.C., USA [21, 24-29].

\begin{tabular}{|c|c|c|c|c|c|c|c|c|}
\hline City & & Port & o Alegre & & & $\mathrm{Wa}$ & ington D.C. & \\
\hline Year & Passengers & Population & Number of cars & $\begin{array}{l}\text { Income per } \\
\text { capita (R\$) }\end{array}$ & Passengers & Population & Number of cars & $\begin{array}{l}\text { Income per } \\
\text { capita }(\$)\end{array}$ \\
\hline 2005 & $276,989,745$ & $1,387,722$ & 424,463 & $16,790,00$ & $270,061,000$ & 515,118 & 180,683 & $44,784,00$ \\
\hline 2006 & $269,561,804$ & $1,392,305$ & 435,209 & $19,691,00$ & $276,926,000$ & 581,530 & 164,598 & $46,448,00$ \\
\hline 2007 & $262,945,196$ & $1,396,430$ & 450,867 & $20,911,00$ & $283,788,000$ & 588,292 & 161,267 & $48,412,00$ \\
\hline 2008 & $315,300,563$ & $1,400,163$ & 472,559 & $25,062,00$ & $292,874,000$ & 591,833 & 171,255 & $48,625,00$ \\
\hline 2009 & $314,763,431$ & $1,404,542$ & 495,915 & $25,675,00$ & $293,397,000$ & 599,657 & 166,519 & $46,236,00$ \\
\hline 2010 & $320,838,663$ & $1,409,351$ & 510,987 & $30,302,72$ & $289,018,000$ & 604,453 & 160,090 & $46,101,00$ \\
\hline 2011 & $323,989,555$ & $1,414,104$ & 529,906 & $34,171,95$ & $290,203,000$ & 617,996 & 238,504 & $47,076,00$ \\
\hline 2012 & $328,706,834$ & $1,417,721$ & 550,289 & $38,260,96$ & $280,904,000$ & 632,323 & 207,048 & $48,825,00$ \\
\hline 2013 & $321,923,051$ & $1,424,618$ & 571,299 & $39,460,23$ & $273,464,000$ & 646,449 & 218,642 & $48,292,00$ \\
\hline 2014 & $302,546,668$ & $1,472,482$ & 587,143 & $43,457,67$ & $271,160,000$ & 658,893 & 222,501 & $49,762,00$ \\
\hline 2015 & $299,209,346$ & $1,476,867$ & 596,446 & $39,091,00$ & $261,435,000$ & 658,893 & 226,436 & $51,146,00$ \\
\hline
\end{tabular}




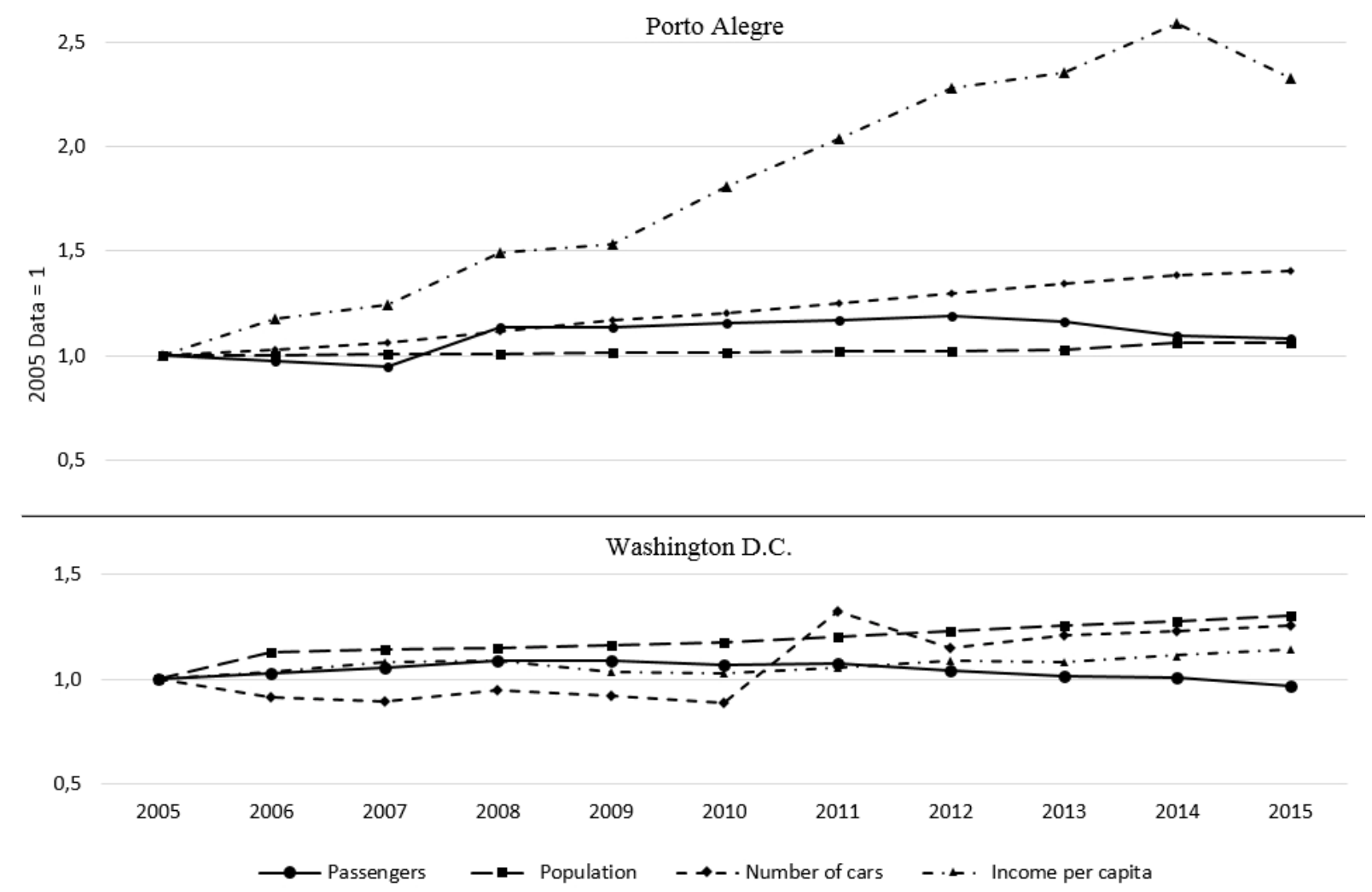

Fig. 3 Correlations between the studied variables.

promotion and effective implementation of alternative transport systems. For instance, bicycles and walks became popular, as well as the focus on the integration of the various modes of public transportation to gradually reduce the use of private cars.

While designing the cited documents, studies were conducted on current patterns of mobility and their relationship with road infrastructure, use and occupation of the soil. However, the moveDC plan is not only limited to current mobility conditions, but statistically traces a social economic and spatial scenario for the year of 2040. The goal is designing a multimodal transport network that can meet the demands of future trips within 25 years. In this regard, the PMPOA (City Hall of Porto Alegre) has its long-term effectiveness reduced, as it projected only the current scenario and considered the fulfillment of this demand as an objective.

In relation to surveys of factors that generate mobility, such as population density, land use, and concentration of jobs, different values are perceived.
PMPOA distinguishes the mobility attractors by categories (educational, health, services), and therefore portrays their influence on the patterns of mobility. MoveDC plan considers the density of jobs and activities (jobs + residents) as an increment for the future scenario (2040).

Regarding population density as a factor of influence on mobility, it can be observed that the PMPOA does not present a population density map that could be used as a complement to the analysis obtained through the distinction of the attractors.

\subsection{Financing Mobility}

This document emphasizes the importance of mobility financing systems that also consider indirect beneficiaries as follows: "impacts and interests related to the implementation, improvement and expansion of transport systems are multiple and differentiated, and extend beyond the borders of the sector" [10].

Indirect beneficiaries (drivers, land owners, and real estate agents) should be included in the sharing of costs 
related to the implementation, expansion and operation of transport modes. For the applicability of these measures, instruments of value collection such as urban tolls, expensive concession of the right to build, and taxation based on the production system are presented. This share of costs related to the operation of public transport tends to make it more financially attractive.

Another way to increase attractiveness of the transport system is tax integration, especially for residents in peripheral areas, who often travel longer distances and may require a combination of modalities to arrive at their destination. This integration of modalities must also extend to active mobility and prioritize the connection of pedestrians and cyclists with public transport. This is due to the fact that they demand significantly less public space than the facilities for cars, such as parking lots or garages [22].

Such measures to encourage active mobility, in addition to the benefit of reducing emission of pollutant gases during journeys, help public authorities and traffic agencies to save money in a long term.

Regarding analyzed plans, the existence of tax integration measures in the city of Porto Alegre is noticed, where a total of 210 public transport (bus) lines are integrated into the Trensurb train line. While in the moveDC plan, measures and objectives are not cited for the effective implementation of tax integration.

Considering that one of the factors of public transport attractiveness should be the lower travel cost than the use of individual transportation, the absence of subsidy policies and tax integration reduces effectiveness of the system. The attractiveness from a financial point of view would result in growth in this transportation system use.

\subsection{Management Efficiency of the Urban Mobility} System: Control and Transparency

Management and operation of public transport services by private companies, as it is usually the case of Brazil, result in concentration of large companies to take control of the market. Furthermore, this grants the private sector the right to put pressure on the public sector and users, thus generating a dispute with these three agents [10].

Alternatives to this mode of operation began to be observed in Europe in the late 1980s, where public enterprises operated and managed transport, and private companies were monitored on strong government regulation. In this model, demands for improvements and transparency in offered services are discussed between government and society. This would facilitate demand fulfillment.

In Porto Alegre, the management of public transport services is carried out by EPTC (Public Transport and Traffic Company), organized as a joint-stock company in charge of planning, financial management, as well as the preparation and approval of plans and projects aimed at mobility [13]. It is noteworthy to mention that in Porto Alegre, the operation of transport systems is divided among four companies, but only one of these companies is public.

In Washington D.C., the management and control of moveDC measures and actions are decentralized. DDOT (Detroit Department of Transportation) is the coordinating agency and works together with other agencies, such as WMATA (Washington Metropolitan Area Transit Authority), National Park Service, Metropolitan Washington Council of Governments and regional partners. It is DDOT's responsibility to identify the projects and initiatives to be directly implemented or those that will be implemented by other agencies, while maintaining control of the projects and initiatives through consultancy.

\subsection{Mobility and Support System for Green Technology}

Transportation systems are a major consumer of the automobile industry, as well as the energy industry. Thus, the structure and operation of public transport presents a sector with great potential for implementation of policies that promote the use of matrix sustainable energy [10]. 
In this context, economic viability of this sector presents itself as a triggering factor for the implementation of sustainable practices. In addition, it contributes to the adoption of non-fossil fuels, and to the incentive to the implementation of large-scale modalities with technologies based on electric energy (subways, VLTs (light rail), and trolleybus). In accordance with the measures suggested in this document, the plans of Porto Alegre and Washington D.C. present actions to be taken for the implementation of energy-based transportation modalities, such as the return of the streetcars in Washington D.C. [13]. Investments on the atmospheric railway in Porto Alegre are also needed [12]. On the other hand, in relation to buses and/or BRTs (bus rapid transit), only Porto Alegre presents the fleet qualification plan, with the use of BRTs, which is supplied with alternative fuels, thus making the system less polluting and with slower depreciation.

\subsection{Implementation of Mobility Policies}

Ways to achieve sustainable mobility, such as reduction of pollutant emissions and incentive to use alternative transports, are a consensus within this topic. However, the implementation of such ways, frequently faces challenges that can be political, social and economic. In this context, the creation of a favorable environment for medium and long-term investments should be considered by including regional planning. Therefore, it could minimize social and environmental impacts, and mitigate the political barriers.

PMPOA seeks to provide with an institutional and operational integration of public transport on a metropolitan scale, and through an integrated multimodal transport network. It also aims at establishing a strict modal integration between urban and metropolitan rail road public systems and their feeding systems. The feasibility of this integrated transport system is based on the following sustainability axes:

- institutional integration: with the creation of a metropolitan transport consortium;

- transport integration, urban and environmental interventions: considering transport as an inducer of urban and environmental requalification and regeneration;

- functional integration of transport: with the creation of the integrated multimodal structural network;

- tax integration: interoperability in ticketing systems;

- integration of control and information to the user: line coding system and fleet standardization;

- financing integration: integrated models of investments with public-private partnerships.

In Washington D.C., the moveDC plan is periodically updated contemplate future changes in the city. It also may be related to financial, political and population trends that are difficult to predict today, but may influence the mobility patterns and demands in the district and its surroundings. There is also concern about possible political barriers in Washington D.C., where some of the measures involve the creation of fees. This would depend on the legislative power to create public policies aiming to improve public transportation system.

Collaboration between management agencies and public transport operations at regional or metropolitan scales enables the integration of fleets through schedules jointly established, thus increasing attractiveness for passengers. This cooperation also makes possible agencies to share employees, facilities, and make joint purchases of supplies with lower marginal costs, contributing to their financial sustainability [22].

\section{Conclusions}

The analyzed plans of Washington D.C. and Porto Alegre present different approaches and instruments for the improvement and effectiveness of the public transportation systems, and their infrastructures. However, in spite of Porto Alegre being located in an 
emerging country, and Washington D.C. in a developed country, there are no discrepancies in the objectives and guidelines outlined in these plans. Among the analyzed factors, the Porto Alegre plan highlights the concern to make public transportation financially attractive to the population, through subsidies and tariff integration, especially to those who need to use more than one transportation line to travel longer distances.

On the other hand, the Washington D.C. plan does not contain in its presentation measures related to fares and travel costs to citizens. However, Washington D.C.'s plan is efficient in relation to planning to meet the infrastructure demand, since it projects the demand for transportation up to the year of 2040. This proactive plan allows more efficiency in infrastructure interventions.

In general, it can be observed that public policies that concern urban mobility can be a strong instrument in the search for urban sustainability. Through the implementation of infrastructure for public transport, subsidies and other legal tools they can induce to the use of alternative means for mobility, while restricting the possibilities of using a private car. However, when analyzing the mobility plans of the studied cities, the lack of restrictive measures in relation to the use of automobiles was also noticed. Such measures could increase attractiveness of other modes of transport, such as the public ones, and improve their financial viability.

Among several factors analyzed here, it is noticed that one of the key elements for effectiveness of the public transport systems and active mobility is to combine their attractiveness to financial sustainability. Thus, urban mobility plans must be designed based on urbanistic concepts to avoid disorderly urban growth. Such growth promotes higher densities, especially along transport axes, makes the system more attractive, and thus reduces the use of individual motor transport. This scenario enables greater efficiency in the use of public funds and optimizes the social and environmental benefits that a sustainable urban mobility plan can provide. In the same context, in addition to promoting higher densities, urbanistic concepts should also encourage diverse use of soil, stimulate local commerce, and therefore reduce distances to be traveled by walking and cycling.

\section{Acknowledgments}

The authors would like to show their thanks to the Postgraduate Support Program for Private Education Institutions (PROSUP) of CAPES (Coordination for the Improvement of Higher Education Personnel) for granting us a scholarship.

\section{References}

[1] Guerra, J. B. S. O. de A., Ribeiroa, J. M. P., Fernandeza, F., Baileya, C., Barbosab, S. B., Neiva, S. da S. 2016. "The Adoption of Strategies for Sustainable Cities: A Comparative Study between Newcastle and Florianópolis Focused on Urban Mobility." Journal of Cleaner Production 113: 681-94.

[2] Marx, R., De Mello, A. M., Zilbovicius, M., and De Lara, F. F. 2015. "Spatial Contexts and Firm Strategies: Applying the Multilevel Perspective to Sustainable Urban Mobility Transitions in Brazil." Journal of Cleaner Production 108: 1092-104.

[3] Rybarczyk, G., and Wu, C. 2010. "Bicycle Facility Planning Using GIS and Multi-criteria Decision Analysis." Applied Geography 30: 282-93.

[4] Ahmad, S., and Oliveira, J. A. 2016 "Determinants of Urban Mobility in India: Lessons for Promoting Sustainable and Inclusive Urban Transportation in Developing Countries." Transport Policy, 1-9.

[5] Dondi, G., Simone, A., Lantieri, C., and Vignali, V. 2011. "Bike Lane Design: The Context Sensitive Approach." Procedia Engineering 21: 897-906.

[6] Curiel-Esparza, J., Mazario-Diez, J. L., Canto-Perello, J., and Martin-Ultrillas, M. 2015. "Prioritization by Consensus of Enhancements for Sustainable Mobility in Urban Areas." Environmental Science \& Policy 55: 248-57.

[7] Hankey, S., Lindsey, G., Wang, X., Borah, J., Hoff, K., Utecht, B., and Xu, Z. 2016. "Estimating Use of Non-motorized Infrastructure: Models of Bicycle and Pedestrian Traffic in Minneapolis, MN." Landscape and Urban Planning 107: 307-16.

[8] Parkes, S. D., Marsden, G., Shaheen, S. A., and Cohen, A. P. 2013. "Understanding the Diffusion of Public 
Bikesharing Systems: Evidence from Europe and North America." Journal of Transport Geography 31: 94-103.

[9] Jones, T., and De Azevedo, L. N. 2013. "Economic, Social and Cultural Transformation and the Role of the Bicycle in Brazil". Journal of Transport Geography 30: 208-19.

[10] Nunes, T., Rosa, J. S., and Moraes, R. F. 2015. Sustentabilidade Urbana: Impactos do Desenvolvimento Econômico e suas Conseqüencias Sobre o Processo de Urbanização em Países Emergentes: Textos para as Discussões da Rio+20: Volume 1 Mobilidade Urbana. Brasília: MMA. 156 p. (in Portuguese)

[11] Fenton, P. 2016. "Sustainable Mobility as Swiss Cheese? Exploring Influences on Urban Transport Strategy in Basel." Natural Resources Forum 1-13, Jun. 2016.

[12] Baiardi, A. 2011. "Elinor Ostrom, a Premiação da Visão Unificada das Ciências Humanas." Caderno Crh 24 (61): 203-16. (in Portuguese)

[13] Prefeitura Municipal de Porto Alegre. 2017. Plano Diretor de Mobilidade Urbana. Porto Alegre, EPTC/Prefeitura Municipal de Porto Alegre. (in Portuguese)

[14] District Department of Transportation. 2014. MoveDC: The District of Columbia Strategic Multimodal Long-Range Plan. Washington D.C.

[15] United States Census Bureau. 2015. American Community Survey 1-Year. Population of District of Columbia.

[16] Buehler, R., and Pucher, J. 2011. "Making Public Transport Financially Sustainable." Transport Policy 18: 126-38.

[17] Instituto Brasileiro de Geografia e Estatística. 2016. Population of Porto Alegre/RS. Accessed December 17, 2016. http://www.ibge.gov.br. (in Portuguese)

[18] Washington Metropolitan Area Transit Authority. 2016. Metro Launches Silver Line, Largest Expansion of Region's Rail System in More than Two Decades. Washington D.C. Accessed July 16, 2016. http://www.wmata.com/about_metro/news/PressRelease Detail.cfm?ReleaseID=5749.

[19] American Public Transportation Association. 2016. Ridership Archives. Accessed December 17, 2016. http://www.apta.com/resources/statistics/Pages/Ridership Archives.aspx.
[20] Empresa Pública de Tranporte e Circulação. 2016. Transporte em Números: Indicadores Anuais do Transporte Público. Accessed 15 december, 2016. http://lproweb.procempa.com.br/pmpa/prefpoa/eptc/usu_ doc/1.apresentacao_indice.pdf. (in Portuguese)

[21] Keller, R., and Vance, C. 2013. "Landscape Pattern and Car Use: Linking Household Data with Satellite Imagery." Journal of Transport Geography 33: 250-7.

[22] Buehler, R., and Pucher, J. 2010. "Making Public Transport Financially Sustainable." Transport Policy 18: 126-38.

[23] Bertaud, A. 2002. "Note on Transportation and Urban Spatial Structure." Presented at the ABCDE Conference. Washington, D.C: World Bank.

[24] QGIS (Open Source Geographic Information System). 2014. Version 2.4: Source Geographic Information System: Project of the Open Source Geospatial Foundation (OSGeo). QGIS.

[25] Osses, M., and Fernandez, R. 2006. "Transport and Air Quality in Santiago, Chile." In Advances in City Transport: Case Studies, 1st ed., Chapter 5, Southampton: WIT Press.

[26] Carvalho, C. H. R., and Pereira, R. H. M. 2011. Efeitos da Variação da Tarifa e da Renda da População Sobre a Demanda de Transporte Público Coletivo Urbano no Brasil. Brasília: Instituto de Pesquisa Economica Aplicada. (in Portuguese)

[27] Instituto Brasileiro de Geografia e Estatística. 2016. Vehicles Fleet of Porto Alegre/RS. Accessed December 17, 2016. http://www.ibge.gov.br. (in Portuguese)

[28] Fundação de Economia e Estatística. 2015. PIB Municipal Série Histórica 2002-2014. Accessed August 28, 2016. http://www.fee.rs.gov.br/indicadores/pib-rs/municipal/ser ie-historica/. (in Portuguese)

[29] Statista. 2016. Number of Registered Automobiles in the District of Columbia. Accessed December 11, 2016. https://www.statista.com/statistics/196031/number-of-reg istered-automobiles-in-the-district-of-columbia/.

[30] U.S. Bureau of Economic Analysis. 2016. Personal Income and Inflation Adjustment. Accessed October 28, 2016. https://www.bea.gov/newsreleases/regional/spi/spi newsrelease.htm. 